\title{
Estudo Sobre a Viabilidade do Seguro Receita: o caso da região oeste do Paraná ${ }^{1}$
}

\author{
Andréia Cristina Oliveira Adami² e Vitor Augusto Ozaki ${ }^{3}$
}

Resumo: Desde 2003, o governo federal tem promovido ações para o desenvolvimento do seguro rural. A principal iniciativa baseia-se no Programa de Subvenção ao Prêmio do Seguro Rural, que garante um nível mínimo de produtividadeem caso de perdas decorrentes de eventos climáticos. Recentemente, algumas seguradoras passaram a disponibilizar em seu portfólio o seguro receita, que visa segurar o produtor contra quedas bruscas em sua produtividade, preços de mercado, ou uma combinação de ambos. Como a experiência brasileira com esse tipo de seguro é nova, o objetivo desse trabalho foi analisar a viabilidade do seguro receita, considerando-se a receita bruta da soja da região oeste do Paraná, em nível de propriedade rural. Os resultados mostraram que as taxas estimadas pelas seguradoras, conhecidas como taxas empíricas, subestimaram o risco para níveis baixos de cobertura (50\% e 60\%). Ao nível de 70\% de cobertura, no entanto, as taxas estimadas pelo modelo (SN) apresentaram o mesmo valor médio para a região como um todo. O fluxo de caixa estimado para as safras 2006/2010 a 2010/2011, por nível de cobertura, apresentou-se positivo para todas as safras, indicando que as operações com o seguro receita geram retorno positivo, apresentando-se como modalidade viável para a atividade.

Palavras-chaves: Seguro receita; Taxa de prêmio; Distribuição normal assimétrica; Política agrícola.

Abstract: Since 2003 crop insurance programs have become the focus of agricultural policy in Brazil. Given the increasing interest in insurance, accurate calculation of premium values has great importance. We address the revenue distribution issue and its implication by pricing a new Brazilian insurance contract, considering the skew-normal distribution of probability of revenue data from the western region of Parana State (Brazil). Results show that insurers (empirical) rates tend to underestimate the risk by lower coverage levels (50\% and 60\%). At $70 \%$ of coverage level, the ER and SN rates seem the same on average. The estimated insured cash flows for 2006/2007 to 2010/2011crops, by coverage level,

1. Data de submissão: 18 de março de 2015. Data de aceite: 9 de março de 2016.

2. Escola Superior de Agricultura "Luiz de Queiroz" - Esalq/USP. Piracicaba, São Paulo, Brasil. E-mail: deiaadami@terra.com.br

3. Escola Superior de Agricultura "Luiz de Queiroz" - Esalq/USP. Piracicaba, São Paulo, Brasil. E-mail: vitorozaki@gmail.com 
were positive for all seasons, indicating that agricultural operations with insurance can generate positive return for insurers, presenting as viable modality for insurance activity.

Key-words: Revenue insurance; Premium rate; Skew-normal distribution; Agricultural policy.

Classificação JEL: Q19.

\section{Introdução}

O Brasil ocupa lugar de destaque no mercado mundial de alimentos por estar entre os maiores produtores e exportadores de produtos agropecuários. Em 2011, o País foi o $4^{\mathrm{O}}$ maior exportador mundial de alimentos, sendo responsável por aproximadamente $6 \%$ do total exportado mundialmente (FOOD AND AGRICULTURE ORGANIZATION OF THE UNITED NATIONS - FAO, 2013). Em 2010, de acordo com dados do Ministério da Agricultura, Pecuária e Abastecimento (BRASIL, 2012), o País ocupou a primeira posição no ranking dos maiores produtores e exportadores mundiais de açúcar, café e suco de laranja. Foi também o segundo maior produtor e maior exportador de carne bovina, tabaco, cana-de-açúcar, etanol e aves. No caso da soja, ocupou a segunda posição tanto como produtor quanto exportador.

Eventos climáticos adversos podem reduzir significativamente o volume de produção, como ocorreu em alguns municípios do Sul do País na safra 2011/2012 e no Centro-Sul do País em meados de 2013, trazendo sérios prejuízos econômicos para o produtor rural e a comunidade local.

A redução significativa na produção esperada da propriedade rural pode comprometer drasticamente a renda em circulação no município ou até mesmo no estado como um todo. Além disso, quedas bruscas de preços também podem impactar negativamente a renda agrícola, prejudicando, além da safra atual, as safras posteriores, já que a redução na renda gera menor disponibilidade de recursos para investimento na unidade de produção agrícola. Devido aos riscos de produção e preços inerentes ao negócio agrícola, crises de endividamento e renegociação de dívidas tornaram-se recorrentes no Brasil.

O seguro rural, como instrumento de política pública, por meio do Programa de Subvenção ao Prêmio do Seguro Rural (PSR), surge como uma alternativa eficiente para amenizar os efeitos de quebra de safra por eventos climáticos (OZAKI, 2010). Para se proteger contra risco de preços, os produtores podem utilizar vários instrumentos, dentre eles contratos de futuros e/ou opções.

Em 2011, algumas seguradoras introduziram em sua gama de produtos o contrato de seguro receita, que é uma nova modalidade de seguro rural e tem por objetivo proteger o produtor rural contra reduções na receita bruta devido à queda da produtividade, reduções de preço de mercado e/ou uma combinação de ambos. Assim, quando a receita cai abaixo do mínimo garantido, o produtor recebe uma indenização, equivalente à diferença entre a receita obtida na safra e a receita garantida em contrato, que é definido no período que antecede o plantio (ISU, 2009; FARMDOC, 2010; SKEES et al., 1998). 
Esse tipo de contrato já existe em outros países. Nos Estados Unidos da América (EUA), desde a metade dos anos 1990, o seguro de receita é operacionalizado e, nos dias atuais, é a principal modalidade de seguro demandado pelos produtores norte-americanos (UNITED STATES DEPARTMENT OF AGRICULTURE/RISK MANAGEMENT AGENCY - USDA/RMA, 2013).

No Brasil, esses contratos ainda estão em fase de desenvolvimento. Um dos parâmetros importantes em qualquer tipo de seguro é a taxa de prêmio. A taxa deve ser calculada utilizando-se metodologia adequada e com o maior número de informações possível para que reflitam com maior confiabilidade o risco do proponente. Taxas de prêmio excessivamente elevadas não atrairiam os produtores e, por outro lado, taxas baixas não seriam atrativas às seguradoras, principalmente pelas características do mercado agrícola: baixa disponibilidade de informações, elevada exposição às catástrofes climáticas e elevados custos de vistorias e fiscalização, além dos problemas de seleção adversa e risco moral (COBLE et al., 1997; JUST, CALVIN e QUIGGIN, 1999).

Para o produtor, uma taxa de prêmio adequadamente calculada, que caracterize seu perfil de risco, seria um dos elementos-chave para a adoção desse seguro; para a seguradora, por outro lado, esse tipo de seguro só seria viável se o montante dos prêmios arrecadados cobrisse as indenizações mais os custos operacionais e administrativos envolvidos nas operações.

Desse modo, nesse artigo busca-se um melhor entendimento do funcionamento desse tipo de seguro e seus resultados tanto para produtores quanto seguradores. Para tanto, foram calculadas as taxas de prêmio atuarialmente justa e a taxa empírica tendo-se como universo de estudo os produtores de soja da região oeste do Paraná, uma das principais produtoras de soja do País e que mais utilizam recursos do PSR (BRASIL, 2015); calculou-se também o resultado financeiro da operação para as safras de 2005/2006 a 2009/2010.

O cômputo da taxa de prêmio é elemento crucial, pois deve refletir a variação da produtivi- dade e a volatilidade dos preços conjuntamente. Alguns estudos da literatura internacional têm mostrado que baixas produtividades são acompanhadas de altos preços de mercados, pois os preços tendem a reagir quando a oferta do produto cai (GOODWIN, ROBERTS e COBLE, 2000). Destaca-se que o foco do trabalho se deu no contrato aplicado aos produtores brasileiros e que não considera a correlação entre produtividade e preço de mercado. Para calcular a taxa de prêmio atuarialmente justa utilizou-se a distribuição normal assimétrica para a receita bruta ao nível de propriedade rural. A escolha da distribuição normal assimétrica se deu pela sua flexibilidade em considerar o parâmetro de assimetria na distribuição de probabilidade da receita agrícola (SANTOS, SCALON e OZAKI, 2014).

É importante ressaltar que a principal contribuição desse trabalho foi analisar a viabilidade de ofertar o seguro receita por parte de uma seguradora por meio do cálculo das taxas de prêmio individuais, e não em nível de município como são calculadas no caso do seguro de custeio agrícola (PSR), as quais foram usadas para o cálculo do fluxo financeiro das operações de seguro rural.

$\mathrm{O}$ artigo está dividido em mais quatro seções além desta introdução. A seguir, há uma breve descrição do mercado de seguro agrícola no Brasil e as especificações do seguro receita em estudo. Em seguida, na seção de metodologia, descreve-se o modelo para cálculo das taxas de prêmio e a distribuição normal assimétrica. Posteriormente, os resultados são apresentados, e ao final têm-se as considerações sobre os resultados da pesquisa.

\section{Seguro de custeio agrícola e seguro receita}

A primeira tentativa brasileira de desenvolver o mercado de seguro rural privado em larga escala no País se deu em 1954 através da Companhia Nacional de Seguro Agrícola (CNSA). A CNSA manteve suas operações até 1966. De 1966 até os anos 1990, apenas algumas companhias estaduais, como a Companhia de Seguros do Estado de 
São Paulo (Cosesp), ofereceram a modalidade de seguro agrícola, mas com cobertura e limite restritos. Nos anos 1990, algumas seguradoras privadas tentaram desenvolver o contrato de seguro agrícola, mas sem sucesso (OZAKI, 2005).

Em 2003, o governo federal, por meio da Lei n. 10.823, criou o Programa de Subvenção ao Prêmio do Seguro Rural (PSR) com o objetivo de estimular o seguro rural no País reduzindo o prêmio do seguro pago pelos produtores rurais. A criação do PSR foi a primeira iniciativa de impacto do Ministério da Agricultura, Pecuária e Abastecimento (Mapa), por meio do Departamento de Gestão de Risco Rural (Deger), no sentido de criar condições para o desenvolvimento do seguro rural. Embora a Lei n. 10.823 tenha sido sancionada em 2003, sua regulamentação ocorreu apenas em 2004, por intermédio do Decreto n. 5.121 (OZAKI, 2008). Em 2005, os percentuais e os limites de subvenção foram determinados pelo Decreto n. 5.514/05.

O Decreto n. 5.514/05 foi revogado pelo Decreto n. 5.782/06 que fixou novos limites e patamares de subvenção para 2006. O novo decreto ainda incluiu novas culturas, além das modalidades pecuária, florestal e aquícola. Ainda em 2006, foi sancionado o Decreto n. 6.002, que fixou os percentuais para o triênio 2007 a 2009. As culturas elegíveis ao PSR permaneceram as mesmas de 2006 até o triênio 2007/09; a única diferença foi o aumento do percentual dos grupos 3 e 4, para $50 \%$ e $40 \%$, respectivamente (Quadro 1).
Apesar de existirem oito modalidades para o seguro rural, apenas quatro delas participam do PSR, sendo: a modalidade agrícola, pecuária, aquícola e florestal. Para cada uma dessas modalidades, os planos trienais determinam os percentuais de subvenção para o período.

A Tabela 1 resume os resultados do PSR, de 2005 a 2014. Observa-se que o programa, apesar de sofrer com problemas de gestão e falta de recursos para seu pleno desenvolvimento, apresentou evolução significativa no Brasil nesse período. O capital segurado aumentou de R\$ 126,6 milhões, em 2005, para quase R\$ 10 bilhões, em 2009, sofrendo também redução nos dois anos posteriores. Área segurada e prêmio arrecadado pelo mercado também apresentaram crescimento elevado durante o período. Esse crescimento foi possível em razão do aumento dos recursos públicos alocados ao PSR. Verifica-se que os recursos utilizados pelo mercado aumentaram de $R$ \$ 2,3 milhões, em 2005, para quase R\$ 260 milhões, em 2009 e R\$254 milhões em 2011. Em 2012, o programa voltou a apresentar aumento no número de apólices contratadas, que chegou a 63.328; a área segurada foi de 5,2 milhões de hectares; o capital segurado atingiu $\mathrm{R} \$ 8.782$ milhões; e os prêmios arrecadados foram de aproximadamente R\$571 milhões. Desde então, o volume de recursos para subvenção continuou a crescer e, em 2014, atingiram os maiores valores alocados ao programa desde 2005. Nesse ano, o número de apólices contratadas chegou a 118.204 unidades,

Quadro 1. Percentuais e limites de subvenção para 2006 e para o triênio 2007/09

\begin{tabular}{|c|c|c|c|c|}
\hline \multirow{2}{*}{ Grupos } & \multirow{2}{*}{ Culturas } & \multicolumn{2}{|c|}{ Subvenção (\%) } & \multirow{2}{*}{$\begin{array}{l}\text { Limite por Produtor } \\
\text { (R\$) }\end{array}$} \\
\hline & & 2006 & $2007 / 09$ & \\
\hline 1 & Feijão, milho segunda safra e trigo & \multicolumn{2}{|c|}{60} & \multirow{7}{*}{32.000} \\
\hline 2 & $\begin{array}{l}\text { Algodão, arroz, aveia, canola, centeio, cevada, milho, soja, sorgo e } \\
\text { triticale }\end{array}$ & \multicolumn{2}{|c|}{50} & \\
\hline 3 & Maçã e uva & 40 & 50 & \\
\hline \multirow[t]{4}{*}{4} & $\begin{array}{l}\text { Abacaxi, alface, alho, ameixa, amendoim, batata, berinjela, beterraba, } \\
\text { café, cana-de-açúcar, caqui, cebola, cenoura, couve-flor, figo, girassol, } \\
\text { goiaba, kiwi, laranja, limão e demais cítricos, morango, nectarina, pepi- } \\
\text { no, pêra, pêssego, pimentão, repolho, tomate e vagem }\end{array}$ & 30 & 40 & \\
\hline & Pecuário & \multicolumn{2}{|c|}{30} & \\
\hline & Florestal & \multicolumn{2}{|c|}{30} & \\
\hline & Aquícola & \multicolumn{2}{|c|}{30} & \\
\hline
\end{tabular}

Fonte: Brasil (2015). 
Tabela 1. Resultados do PSR - de 2005 a 2014

\begin{tabular}{cccccc}
\hline Ano & $\begin{array}{c}\text { Apólices } \\
\text { (un) }\end{array}$ & $\begin{array}{c}\text { Subvenção Total } \\
\text { (Milhões R\$) }\end{array}$ & $\begin{array}{c}\text { Área segurada } \\
\text { (Milhões ha) }\end{array}$ & $\begin{array}{c}\text { Capital segurado } \\
\text { (Milhões R\$) }\end{array}$ & $\begin{array}{c}\text { Prêmio Total } \\
\text { (Milhões R\$) }\end{array}$ \\
\hline 2005 & 849 & 2,3 & 0,07 & 127 & 8,7 \\
2006 & 21.779 & 31,1 & 1,56 & 2.869 & 71,1 \\
2007 & 31.637 & 60,9 & 2,28 & 2.706 & 127,7 \\
2008 & 60.120 & 157,5 & 4,76 & 7.209 & 324,7 \\
2009 & 74.166 & 259,6 & 6,67 & 9.684 & 477,8 \\
2010 & 52.880 & 198,2 & 4,79 & 6.542 & 368,1 \\
2011 & 57.885 & 253,5 & 5,58 & 7.339 & 466,4 \\
2012 & 63.382 & 318,1 & 5,24 & 8.782 & 571,4 \\
2013 & 101.850 & 557,8 & 9,6 & 16.843 & $1.001,4$ \\
2014 & 118.204 & 693,5 & 9,9 & 18.598 & $1.236,7$ \\
\hline
\end{tabular}

Fonte: Brasil (2015).

a área segurada foi de 9,96 milhões de hectares, o capital segurado atingiu $\mathrm{R} \$ 18.598$ milhões, os prêmios arrecadados foram de aproximadamente $\mathrm{R} \$ 1,236$ bilhão e o governo federal alocou ao programa o valor recorde de $\mathrm{R} \$ 693$ milhões (BRASIL, 2015).

Para o triênio 2010/2012, ogoverno federal definiu os valores máximos de subvenção ao prêmio do seguro rural, por beneficiário (pessoa física ou jurídica), em cada ano civil, que foram estabelecidos em:

- Modalidade agrícola: R\$96.000,00 e

- Modalidades pecuária, florestal e aquícola: $\mathrm{R} \$ 32.000,00$.

O produtor poderia receber a subvenção para mais de uma modalidade, desde que o somató- rio do benefício não ultrapassasse o valor máximo de $\mathrm{R} \$ 192.000,00$ por ano civil (BRASIL, 2015). Também foi possível contratar o seguro rural utilizando recursos da subvenção ao prêmio para a mesma atividade na qual existisse operação de crédito enquadrada no Proagro, para lavouras implantadas em áreas diferentes.

No Quadro 2 apresentam-se os limites de subvenção previstos no orçamento do governo federal para 2013 e 2014. Os limites de subvenção por produtor, em R\$, foram mantidos para 2013 e 2014 no mesmo nível aplicado ao triênio 20102012 (Quadro 2).

No entanto, os percentuais de subvenção foram alterados de forma a adequar a aplicação dos recursos do PSR às prioridades do plano agrícola para a safra 2013/2014. Assim, para as culturas

Quadro 2. Percentuais e limites de subvenção para o triênio 2013 e 2014

\begin{tabular}{|l|l|c|}
\hline \multicolumn{1}{|c|}{$\begin{array}{c}\text { Modalidade } \\
\text { de Seguro }\end{array}$} & \multicolumn{1}{|c|}{ Grupos de culturas } & Limite por Produtor (R\$) \\
\hline Agrícola & $\begin{array}{l}\text { Abacate, abacaxi, abóbora, abobrinha, alface, algodão, alho, ameixa, } \\
\text { amendoim, arroz, atemoia, aveia, banana, batata, berinjela, beterraba, } \\
\text { cacau, café, caju, cana-de-açúcar, canola, caqui, cebola, cenoura, cevada, } \\
\text { centeio, cherimoia, chuchu, couve-flor, ervilha, escarola (chicória), fava, } \\
\text { feijão, figo, girassol, goiaba, graviola, jiló, laranja, lichia, lima, limão } \\
\text { e demais cítricos, linho, maça, mamão, mamona, mandioca, manga, } \\
\text { maracujá, melancia, melão, milho, milho segunda safra, morango, } \\
\text { nectarina, pepino, pêra, pêssego, pimentão, pinha, quiabo, repolho, } \\
\text { sisal, soja, sorgo, tangerina, tomate, trigo, triticale, uva, vagem e demais } \\
\text { hortaliças e legumes. }\end{array}$ & \multirow{2}{*}{$96.000,00$} \\
\hline Pecuário & Aves, bovinos, bubalinos, caprinos, equinos, ovinos e suínos & $32.000,00$ \\
\hline Florestal & Silvicultura & \\
\hline Aquícola & Arcinicultura, maricultura, piscicultura & \\
\hline
\end{tabular}

Fonte: Brasil (2015). 
e microrregiões consideradas como prioritárias como: algodão, ameixa, arroz, caqui, feijão, maçã, milho, pêssego, soja e uva, os percentuais de subvenção foram fixados em $60 \%$.

Todas as culturas produzidas por produtores enquadrados no Programa Nacional de Apoio ao Médio Produtor Rural/Pronamp, independente da região produtora, também tiveram os limites de subvenção fixados em $60 \%$, assim como a modalidade Florestal. Já as demais modalidades de seguro rural, independente da atividade subvencionável e região, tiveram os percentuais de subvenção fixados em 40\% (BRASIL, 2015).

Mais recentemente, em 2015, o programa teve novas alterações em seus limites de taxas e valores de subvenção para se adequar ao novo cenário de maior restrição fiscal (BRASIL, 2015).

OPSR é fundamental para o desenvolvimento do mercado na medida em que reduz o preço do seguro, viabilizando a contratação por parte dos produtores rurais. Algumas implicações diretas desse fato são o aumento da demanda pelos produtores e o melhor gerenciamento do risco por parte das empresas seguradoras na medida em que ocorre maior pulverização do risco nas diversas regiões do País (OZAKI, 2010).

Ressalta-se que os recursos disponibilizados para o PSR são orçados no ano anterior com base nas expectativas das seguradoras da demanda para subvenção por produto e modalidade de seguro rural. Desta forma, os recursos orçados em 2004 e utilizados em 2005 foram da ordem de R\$ 10 milhões. Porém, apenas R \$2,3 milhões foram demandados pelo mercado. Na Figura 1 mostra-se a evolução dos recursos orçados e os gastos efetivos.

Percebe-se que tanto os recursos alocados ao PSR quanto os gastos efetivos cresceram ano a ano desde 2005 (Figura 1). Até 2008, os recursos foram suficientes para cobrir a demanda do mercado. Em 2009, no entanto, a demanda superou os recursos disponibilizados pelo governo em R\$ 90 milhões em virtude do atraso do pagamento da subvenção às seguradoras.

Apesar de o governo ter sancionado a lei para liberação dos recursos, ainda assim, o orçamento inicial de R 238 milhões foi reduzido para R\$ 190 milhões. Em 2011, dos R \$406 milhões orçados, apenas R $\$ 253,5$ milhões foram efetivamente alocados ao PSR. Em 2012, a subvenção federal chegou a R\$ 318 milhões. Mesmo com todos os problemas de gestão, em 2013 o programa retomou a trajetória de crescimento que vinha apresentando até 2009 e, da previsão de alocação de recursos da ordem $\mathrm{R} \$ 750$ milhões, $\mathrm{R} \$ 557,8$ milhões foram efetivamente gastos; já em 2014 o valor subvencionado chegou ao recorde de R\$ 693 milhões.

Figura 1. Evolução dos recursos liberados e gastos efetivos, no período de 2005 a 2011, em milhões de reais

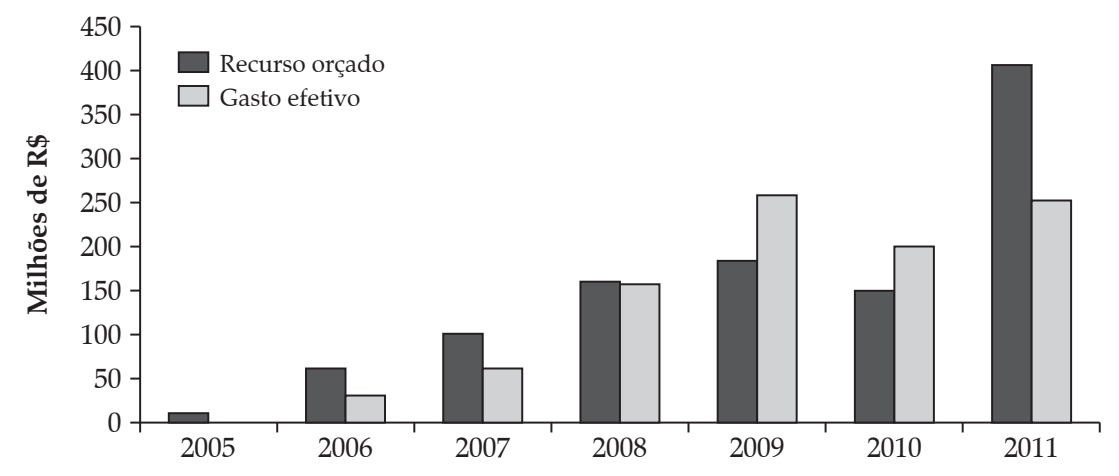

Fonte: Brasil (2015). 
Medeiros (2013) avaliou o PSR e concluiu que o programa vem produzindo resultados positivos se comparados aos seus objetivos de política pública, uma vez que o número de produtores atendidos e a área segurada têm se elevado no período de sua implementação. Contudo, o programa não tem atingido eficácia plena, pois há interesse pela adesão ao Programa, mas seu estudo demonstrou a necessidade de se avançar em alguns pontos, como o efetivo exercício do papel do Comitê Gestor Interministerial do Seguro Rural e a garantia dos recursos necessários para atender a demanda de contratação do seguro, que são condições necessárias para o avanço da política pública.

O PSR é um programa que visa proteger o produtor contra os riscos climáticos que afetam o volume de produção e, portanto, a oferta do produto. No entanto, algumas regióes do País são menos suscetíveis ao risco climático, como a região Centro-Oeste. Para essa região, a volatilidade de preços pode ser mais crítica do que a perda de produção por risco climático. Numa tentativa de resolver o problema, desde 2011, algumas seguradoras incluíram em seu portfólio o seguro de receita.

Nesse tipo de seguro é oferecido ao produtor rural proteção contra a queda de sua receita, garantindo de forma conjunta preço e produtividade. Há que se ressaltar que até o momento não existe legislação específica para o seguro de receita, no entanto, essas operações têm recebido apoio do governo federal por meio dos recursos alocados ao PSR.

O seguro receita em estudo garante a receita do produtor rural contra queda de produtividade, preço ou uma combinação de ambos, suportando um nível mínimo da receita da propriedade rural. O nível de garantia é único para cada produtor e depende da cotação, em dólares americanos (USD), dos preços futuros da saca de soja (60 quilos) com vencimento para março (período da colheita brasileira); da produtividade média da propriedade rural nos últimos cinco anos e do nível de cobertura escolhido pelo produtor, que pode ser de $50 \%, 60 \%$ ou $70 \%$.

\section{Metodologia}

\subsection{Taxa de prêmio do Seguro Receita}

A taxa de prêmio é parâmetro crítico em qualquer contrato de seguro. Produtores com baixo nível de risco podem ser sobreprecificados e não terão incentivos para contratar o seguro, enquanto aqueles com alto nível de risco podem ser subprecificados e apresentarão maior disposição a aderir aos contratos de seguro. Essa distorção em favor daqueles com maior nível de risco poderá levar a carteira agrícola à ruína, pois o montante arrecadado com os prêmios será insuficiente para cobrir as indenizações. Na literatura da economia do seguro esse fato é conhecido como problema de "seleção adversa".

A situação ideal é aquela em que a seguradora precifica com base na produtividade esperada de cada unidade segurada, considerando o risco e as peculiaridades de cada unidade produtora. No entanto, tais séries históricas são escassas, o que dificulta sobremaneira o cálculo das taxas. Ademais, aquelas existentes são provenientes das cooperativas ou empresas de insumos agrícolas, que são as partes interessadas na negociação do risco com a seguradora.

No caso do seguro de receita, as informações sobre produtividade devem ser disponibilizadas em nível de propriedade rural e não em nível municipal, como no caso do seguro de custeio, e é necessário que haja um histórico das produtividades obtidas pelos produtores nos últimos cinco anos. O nível de cobertura é escolhido pelo produtor entre $50 \%, 60 \%$ ou $70 \%$, e os preços, em geral, são definidos de acordo com a cotação do preço futuro, em dólares americanos, do contrato com vencimento na época da colheita (março de cada ano).

Tradicionalmente, o método usado pelo mercado para a precificação do risco, tanto de custeio quanto de receita, é baseado na relação entre as perdas esperadas e o valor garantido pela empresa seguradora, conhecido como "taxas empíricas" (ER). Uma das principais desvantagens do método ER é a dependência de 
um grande número de informações para refletir acuradamente a distribuição de probabilidade da produtividade ou da receita.

De modo a resolver esse problema, assume-se nesse trabalho que a receita da propriedade agrícola siga uma distribuição normal assimétrica, que incorpora um parâmetro flexível para captar, caso exista, a assimetria da distribuição de probabilidade. Optou-se pela distribuição normal assimétrica em função de sua flexibilidade e devido a evidências de assimetria na distribuição da produtividade agrícola e da receita agrícola em estudos anteriores (SHERRICK et al., 2004; OZAKI e SILVA, 2009; SANTOS, SCALON e OZAKI, 2014).

A fórmula de precificação sob a pressuposição de normalidade assimétrica (SN) representa o resultado esperado, como proporção ou percentagem, em relação ao total da Receita Garantida. A proporção $\lambda,(0 \leq \lambda \leq 1)$, que é o nível de cobertura, a produtividade esperada da propriedade agrícola $\left(y^{\mathrm{e}}\right)$ e o preço médio do contrato futuro com vencimento no mês de março próximo para a saca de soja $(P G)$ foram utilizados para obter a Receita Garantida ( $\left.F G=\lambda * y^{*} P G\right)$ no momento da contratação do seguro, em meados de setembro de cada ano. Com base nessas informações, a taxa de prêmio foi dada por:

$$
\begin{aligned}
& S N=\frac{F_{Y P}\left(\lambda y^{e} P G\right) \cdot E_{Y P}\left[\lambda y^{e} P G-E\left(Y P / p y<\lambda P G y^{e}\right)\right]}{\lambda y^{e} P G}= \\
& =\frac{\int_{0}^{\lambda y^{e} P G}\left(\lambda y^{e} P G-y p\right) f(y p) d y p}{\lambda y^{e} P G}
\end{aligned}
$$

Em que $E$ é o operador de esperança, $p$ é o preço futuro no período da colheita, $y$ é a produtividade agrícola obtida na colheita, $f$ é a função densidade de probabilidade da receita obtida $(y p)$ e $F$ é a função de distribuição acumulada da receita obtida (yp).

\subsection{Distribuição normal assimétrica}

Azzalini (1985) propôs um método para construir a distribuição normal assimétrica baseado no parâmetro de assimetria dessa distribuição.
Considerando-se que $f$ seja a função densidade de probabilidade $(p, d, f)$ simétrica em 0 e $G$ uma função de distribuição acumulada contínua e absoluta $(c, d, f)$, tal que $g=G^{\prime}$ é simétrica em 0 , então:

$$
2 f(x) G(\theta), x \in R
$$

A função definida em (1) é uma p.d.f. para qualquer $\theta \in R$. Da equação (1) pode-se derivar a distribuição normal assimétrica (SN), com parâmetro de locação $\mu$, parâmetro de escala $\sigma$ e parâmetro de assimetria $\theta$, conforme definido pela seguinte - equação (2):

$$
\phi(x / \theta, \mu, \sigma)=\frac{2}{\sigma} \phi\left(\frac{x-\mu}{\sigma}\right) \Phi\left(\frac{\theta(x-\mu)}{\sigma}\right)
$$

Na equação (2), ф e Ф são a p.d.f. e a c.d.f. de uma distribuição normal padrão da variável aleatória, respectivamente. Pode-se medir o grau de assimetria da distribuição normal assimétrica dada pela equação (2) por:

$$
\gamma=\delta^{3}\left[\frac{4}{\pi}-1\right]\left[1-\frac{2 \delta^{2}}{\pi}\right]^{3 / 2} \sqrt{\frac{2}{\pi}}
$$

Em (3), $\delta=\theta\left(1+\theta^{2}\right)$ e $-0,99527<\gamma<0,99527$ com limites no intervalo $(\theta \rightarrow \pm \infty)$, representando uma distribuição meio-normal. Este desenvolvimento segue a proposta de Henze (1986), que representou a distribuição normal assimétrica como a media-variância da mistura de uma distribuição normal com a meio-normal. Genton (2004) mostra mais detalhes da distribuição multivariada normal assimétrica e outras distribuições assimétricas.

\subsection{Descrição da base de dados}

As séries de produtividade utilizadas neste estudo são provenientes da Coamo Agroindustrial Cooperativa, de Campo Mourão, Paraná, e foram consideradas em sacas de 60 quilos por hectare para cada propriedade rural da região oeste do estado estratificada na amostra. A cooperativa conta com 116 unidades localizadas em 67 muni- 
cípios nos estados do Paraná, Santa Catarina e Mato Grosso do Sul, para recebimento da produção agrícola dos seus mais de 26 mil cooperados. A amostra tem informações de 585 propriedades rurais para dez safras, iniciando na safra 2000/2001. O estado do Paraná é o segundo maior produtor de soja do País e colheu aproximadamente 17\% de toda a produção brasileira na safra 2011/2012.

Para cálculo da receita da região, foram consideradas também as cotações médias de fevereiro dos preços diários do contrato futuro com vencimento em março, transacionados na bolsa de Chicago (CME - CHICAGO EXCHANGE FUTURES MARKET, 2013). Esses preços foram convertidos de dólares para Reais pela taxa de câmbio ptax, média de fevereiro.

\section{Resultados e discussão}

O seguro rural na modalidade Receita Agrícola em operação no Brasil e objeto desse estudo tem por objetivo garantir receita mínima ao produtor rural contra queda de produtividade, preço e/ou uma combinação de ambos, mantendo, assim, um nível mínimo da receita bruta ao produtor rural. O nível de garantia é único para cada produtor, e depende da cotação, em dólares americanos (USD), dos preços futuros da saca de soja (60 quilos) com vencimento em março (período da colheita brasileira); da produtividade média da propriedade rural nos últimos cinco anos e do nível de cobertura escolhido pelo produtor, que pode variar entre $50 \%, 60 \%$ e $70 \%$.

$\mathrm{Na}$ Tabela 2 são comparadas as taxas ER e SN estimadas para as 585 propriedades rurais da região oeste do Paraná. Foram obtidas estimativas das taxas individuais e as médias municipais para cada nível de cobertura, 50\%, 60\% e $70 \%$. Os municípios considerados foram: Tupassi, Bragantina, Spiguaçu, O.V.Oeste N.Sta.Rosa, VilaNova, eDezMaio. É possível observar que, para alguns municípios, as taxas ER foram subestimadas e, em outros casos, superestimadas, comparando-as com as taxas $\mathrm{SN}$.

Quando há sobreprecificação, ER > SN, e o agente segurado possui menor nível de risco do que o considerado pela seguradora.Por outro lado, nos casos em que há subprecificação, $\mathrm{ER}<\mathrm{SN}$ e, assim, considera-se menor nível de risco do que o apresentado pelo segurado.

Ao nível de cobertura de $70 \%$, a diferença se reduz comparativamente aos níveis de $60 \%$ e $50 \%$ para todos os municípios. Ao nível regional (média da região oeste), as diferenças entre as duas taxas também se reduzem quando os níveis de cobertura aumentam e, para o nível de $70 \%$ de cobertura, ambas as taxas médias da região oeste estiveram em $5,4 \%$.

Na Figura 2 mostra-se a taxa ER e, na Figura 3, a taxa SN. A comparação entre as duas taxas mostra importantes diferenças, pois produtores com maior nível de risco tiveram suas taxas ER subestimadas, o que significa uma taxa

Tabela 2. Normal Assimétrica (SN) e taxas empíricas (ER) - estimativas para os diferentes níveis de cobertura para a região oeste do Paraná, por município

\begin{tabular}{ccccccc}
\hline \multirow{2}{*}{ Município } & \multicolumn{2}{c}{ NC50\% } & \multicolumn{3}{c}{ NC60\% } & \multicolumn{3}{c}{ NC70\% } \\
\cline { 2 - 7 } & ER(\%) & SN(\%) & ER(\%) & SN(\%) & ER(\%) & SN(\%) \\
\hline Tupassi & 3,3 & 4,3 & 4,9 & 5,9 & 7,1 & 8,0 \\
Bragantina & 1,2 & 2,4 & 2,8 & 3,6 & 4,7 & 5,3 \\
Spiguaçu & 0,7 & 1,7 & 1,9 & 2,5 & 4,6 & 3,8 \\
O. V. Oeste & 1,1 & 1,8 & 2,6 & 2,7 & 5,2 & 4,1 \\
Toledo & 0,6 & 1,1 & 1,7 & 1,9 & 3,9 & 3,0 \\
N. Sta. Rosa & 3,2 & 2,3 & 3,0 & 3,5 & 5,0 & 5,2 \\
Vila Nova & 1,4 & 1,9 & 2,9 & 2,8 & 5,2 & 4,1 \\
DezMaio & 0,7 & 2,0 & 2,4 & 3,2 & 3,7 & 5,9 \\
\hline Região Oeste & 1,8 & 2,6 & 3,2 & 3,8 & & 5,4 \\
\hline
\end{tabular}

Fonte: Resultados do estudo. 
Figura 2. Taxa ER estimada pra toda região oeste do Paraná, em nível de propriedade rural

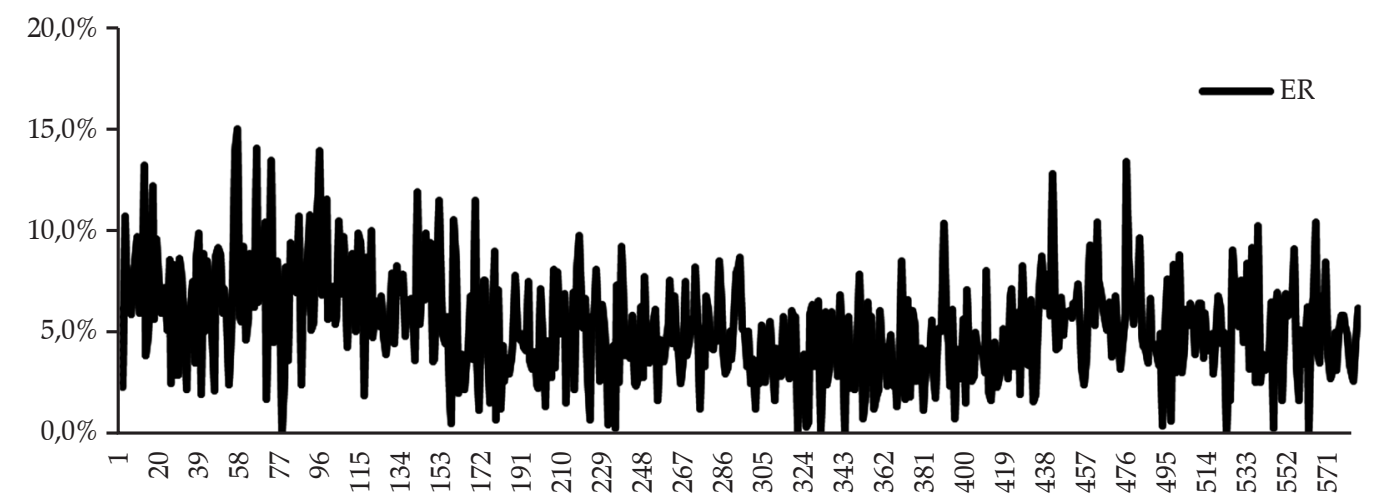

Fonte: Dados da amostra.

Figura 3. Taxa SN estimada pra toda região oeste do Paraná, em nível de propriedade rural

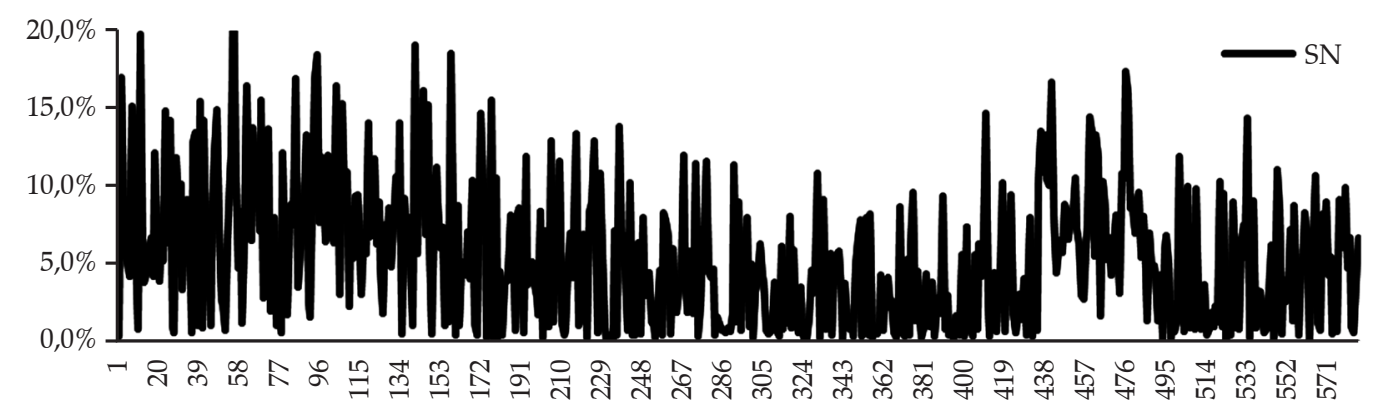

Fonte: Dados da amostra.

ER menor do que a SN. Por outro lado, produtores com menor nível de risco apresentaram taxas ER maiores do que as taxas estimadas SN. Isso significa que alguns produtores foram sobreprecificados, enquanto outros foram subprecificados, de acordo com as taxas SN calculadas. Este fato tende a reduzir a demanda pelo seguro por parte daqueles que possuem alto valor esperado de receita bruta e baixo nível de risco, enquanto a demanda por parte dos produtores que apresentaram baixo valor esperado de receita e alto nível de risco tende a crescer, o que pode gerar no futuro volume de prêmio arrecadado insuficiente para contrapor as indenizações.

As Figuras 4, 5 e 6 mostram as diferenças entre as taxas ER e SN (ER-SN) em termos de propriedade rural para cada nível de cobertura. Quando a diferença é positiva, a taxa ER foi superesti- mada e o produtor, sobreprecificado, e quando a diferença é negativa, a taxa ER foi subestimada e $\mathrm{o}$, produtor subprecificado.

Ao nível de 50\% de cobertura, grande parte dos produtores foi subprecificada (Figura 4); o que é indicado pelo grande número de valores negativos no gráfico. Ao nível de $60 \%$ de cobertura essa parcela se reduz (Figura 5), mas ainda há vários produtores subprecificados na amostra. O mesmo acontece ao nível de $70 \%$ de cobertura (Figura 6), e é possível verificar que,neste caso, há vários produtores sobreprecificados na amostra.

As taxas estimadas, individuais e médias regionais mostraram que há diferenças e problemas de precificação do risco em nível individual, embora em nível regional essas diferenças sejam menores. 
Figura 4. Diferenças entre a taxa ER e SN por propriedade rural ao nível de cobertura de 50\%

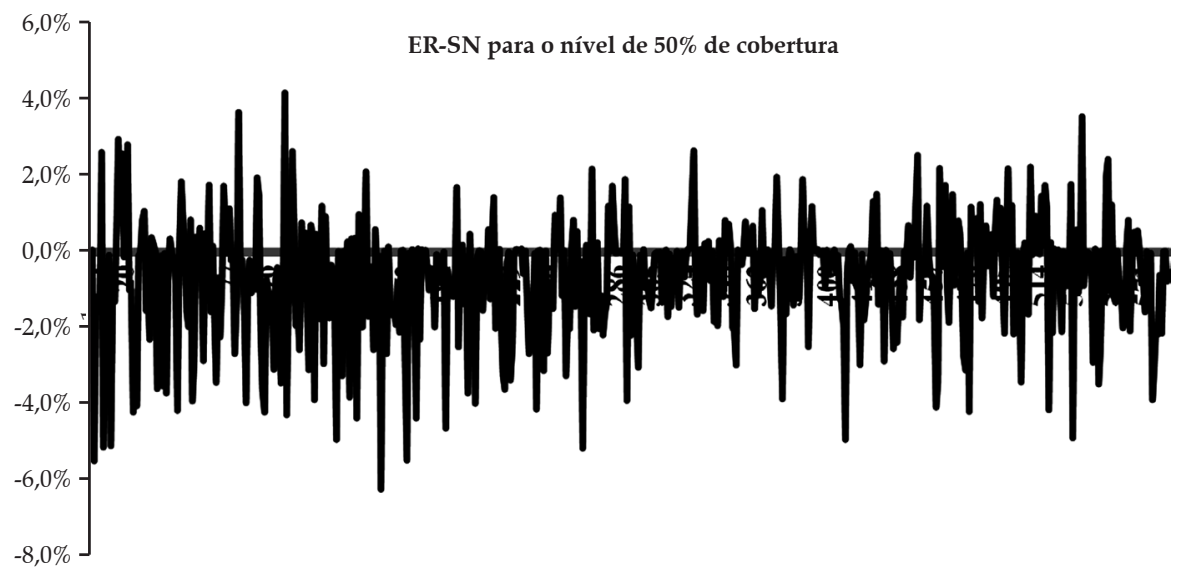

Fonte: Dados da pesquisa.

Figura 5. Diferenças entre a taxa ER e SN por propriedade rural ao nível de cobertura de $60 \%$

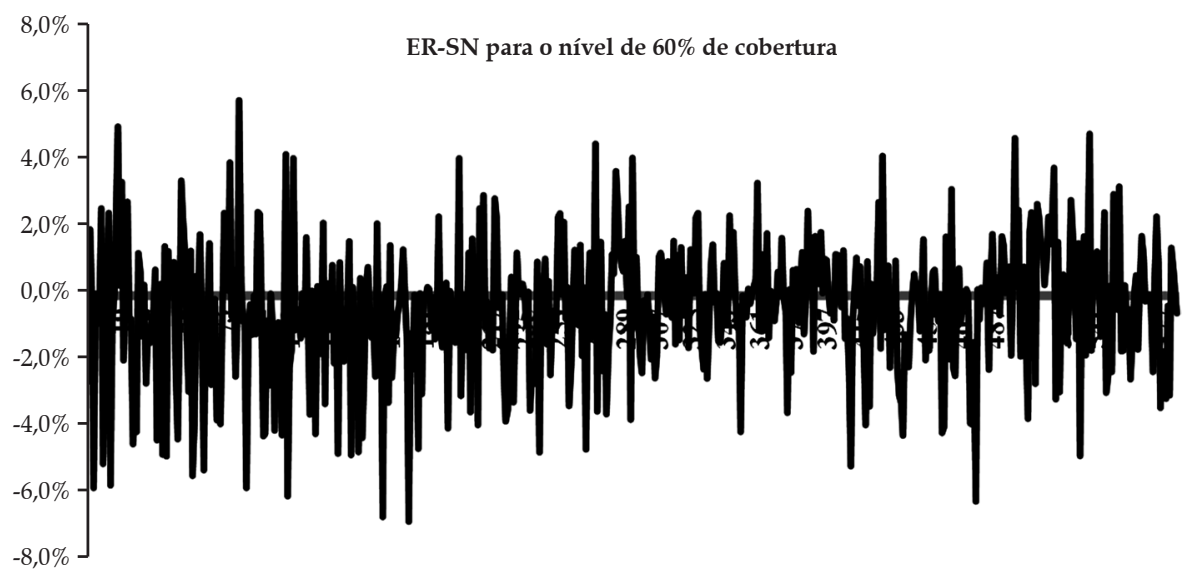

Fonte: Dados da pesquisa.

Figura 6. Diferenças entre a taxa ER e SN por propriedade rural ao nível de cobertura de 70\%

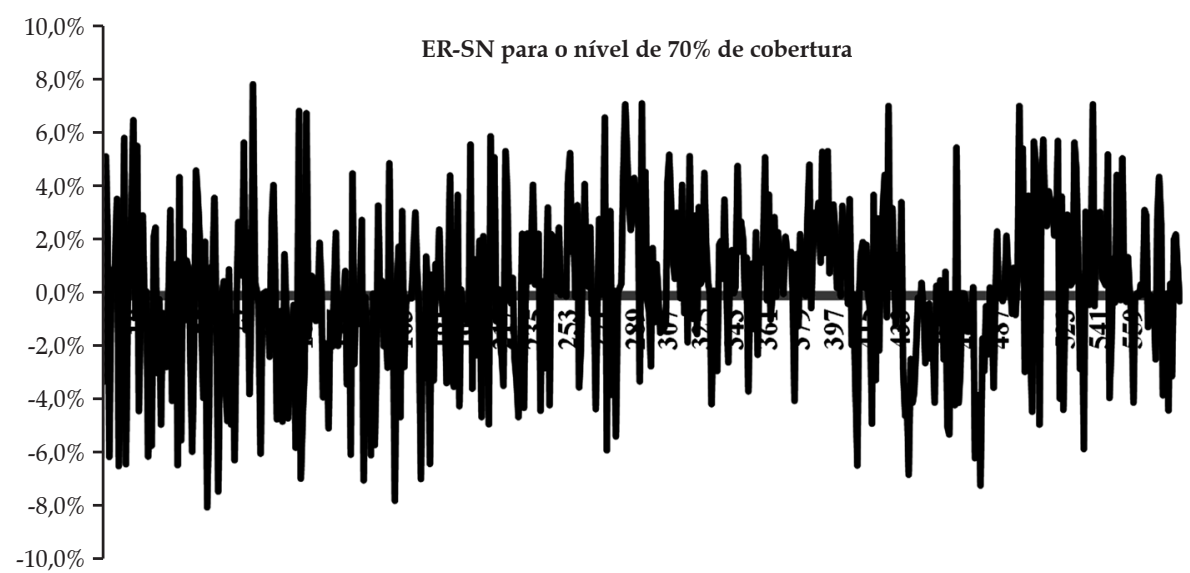


Para a seguradora, em termos financeiros, a taxa de prêmio constitui a receita da companhia com as operações de seguro agrícola, ou seja, o montante monetário arrecadado pela empresa durante o período do plantio. Embora o grau de exposição da seguradora no mercado de soja não seja conhecido com certeza, as receitas devem ser suficientes para cobrir as indenizações no período da colheita em anos de clima favorável, mas podem ser insuficientes em anos de secas severas ou graves geadas. Assim, devido às diferenças nas taxas estimadas individualmente, é importante avaliar o fluxo de caixa da operação em nível de propriedade rural e agregado, para avaliar o risco que o segurador corre de não conseguir cobrir as indenizações devidas.

$\mathrm{Na}$ Figura 7 são apresentados os fluxos de caixa estimados para as safras 2006/2007 a 2010/2011 para os níveis de cobertura de $70 \%$, $60 \%$ e $50 \%$. Esse fluxo é resultado das operações dos 585 produtores amostrados na região oeste do Paraná e de acordo com as especificações do seguro receita. Observa-se que, para níveis maiores (NC60\% e NC70\%) de cobertura, a operação geraria retornos superiores aos gerados para níveis menores de cobertura (NC50\%).

Embora existam vários casos em que as indenizações foram superiores à arrecadação com o prêmio, principalmente na safra 2008/2009, quando a região sofreu quebra de $20 \%$ da produção, em nível agregado, todas as safras geraram fluxo de caixa positivo. Isso indica que as opera- ções de seguro podem e geraram retorno positivo, apresentando-se como modalidade viável pra atividade seguradora. Ressalta-se, no entanto, que a taxa calculada refere-se a apenas uma parte das receitas das seguradoras. Existem outros carregamentos, como por exemplo os custos administrativos, operacionais e o lucro da seguradora que são acrescidos à taxa efetivamente cobrada pelas seguradoras. No estudo, tais carregamentos não foram contabilizados. Nesse contexto, nota-se que os resultados para as seguradoras poderiam ter sido até melhores, uma vez que as taxas praticadas são maiores do que as calculadas no estudo.

\section{Considerações finais}

Nesse estudo foi considerada a distribuição normal assimétrica para o cálculo da taxa de prêmio e, a partir disso, obteve-se a receita bruta obtida pelos produtores de soja da região oeste do Paraná. As taxas foram comparadas com as taxas empíricas (ER), utilizadas pelas companhias seguradoras no Brasil para precificar o risco agrícola. Esse método baseia-se na relação entre as perdas esperadas e o nível de receita garantido e depende de um número grande de observações para refletir acuradamente a distribuição de probabilidade da variável receita.

Os resultados mostraram que, em nível de propriedade rural, a taxas estimadas $\mathrm{SN}$ diferiram das taxas empíricas ER; no entanto, as

Figura 7. Fluxos de caixa das operações de seguro receita das safras 2006/2007 a 2010/2011 por nível de cobertura

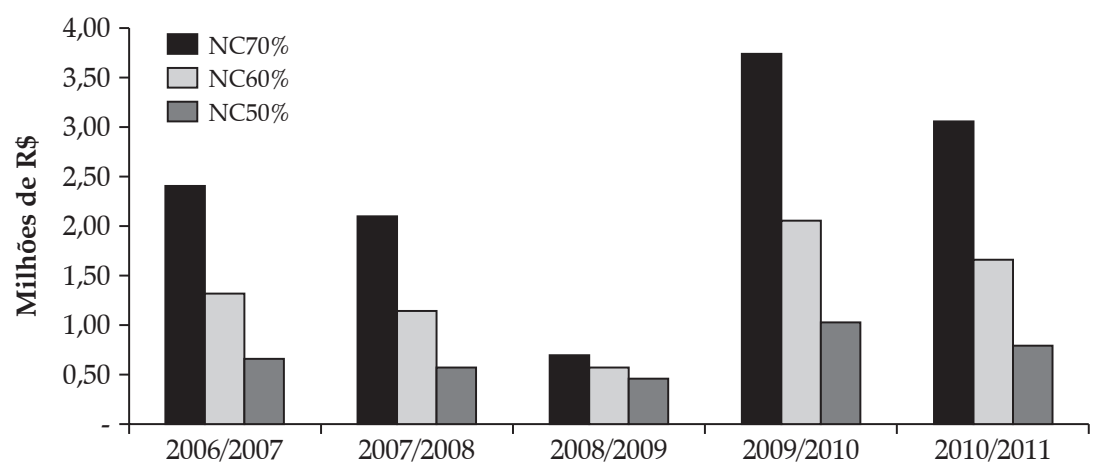

Fonte: Elaborado pelos autores a partir dos dados da pesquisa. 
diferenças se reduzem em nível agregado, e para o nível de $70 \%$ de cobertura as taxas são iguais, em média, para a região oeste. Dessa forma, há casos em que os agentes segurados podem estar sendo sobreprecificados e outros, subprecificados. Para tornar o seguro atrativo ao produtor, o governo federal tem atuado por meio de subvenção econômica (PSR), o que tem reduzido o preço pago pelos produtores e viabilizado as operações com o seguro rural.

Os fluxos de caixa estimados com essas operações também mostraram que há viabilidade para a companhia seguradora, pois em todas as safras pesquisadas, no agregado, os fluxos financeiros estimados foram positivos, indicando que essa modalidade de seguro pode gerar retorno positivo mesmo em anos de quebra de safra por problemas climáticos, como ocorreu na safra 2008/2009.

Mesmo com os avanços obtidos desde 2005 com o programa, há problemas que ainda permanecem. O mercado de seguro rural no Brasil necessita de melhorias no seu sistema de informação, tanto público quanto privado. Informações em nível mais desagregado, em nível de propriedade, por exemplo, seriam importantes para o conhecimento do perfil de risco de cada unidade segurada e contribuiria para o desenvolvimento de produtos que melhor atendessem as expectativas dos segurados, dos seguradores e agentes envolvidos no agronegócio brasileiro, de modo a reduzir os problemas de subprecificação e sobreprecificação. Sugere-se também que novos estudos sejam desenvolvidos considerando-se outros intervalos de preços para os períodos de contratação e fechamento do contrato de modo a testar novas possibilidades para o seguro de receita, o que ajudaria a avaliar se o fator tempo poderia interferir no resultado final do contrato, acarretando maiores ou menores volumes de indenizações.

Como instrumento de política pública, a modalidade de seguro receita atende as necessidades tanto dos produtores da região Sul, que sofrem mais com problemas climáticos, quanto do Centro-Oeste, duas principais regiões produtoras, que têm reivindicado alterações na política de seguro rural, pois são mais afetadas pela volatilidade dos preços. Ainda, a análise proposta é relevante, pois é a primeira análise a mostrar evidências de que o fluxo financeiro das seguradoras tem sido positivo mesmo em anos de quebra de safra por problemas climáticos, fato que indica que há espaço para se discutir os percentuais do prêmio, uma vez que mesmo em anos de perdas graves por problemas climáticos existe margem para se operacionalizar o seguro.

Como limitações ressalta-se o fato de que o estudo abrange uma região importante, mas limitada quando se considera todo o mercado de soja. Os resultados podem ser extrapolados para regiões com comportamento edafoclimático e nível tecnológico semelhantes aos da região estudada, visto que o risco de preço é uma variável constante, mas deve ser interpretada com relativa cautela nas regiões com características distintas do oeste do Paraná.

\section{Referências}

AZZALINI, A. A class of distributions which includes the normal ones. Scand J. Statist, v. 12, pp. 171-178, 1985.

BRASIL. Ministério da Agricultura, Pecuária e Abastecimento - MAPA. Política Agrícola. Disponível em: <http://www.agricultura.gov.br/politica-agricola/ seguro-rural >. Acesso em: 10 dez. 2015. Ministério da Agricultura, Pecuária e
Abastecimento - MAPA. Agronegócio brasileiro em
números. Disponível em: <http://www.slideshare.
net/MinAgriculturaBrasil/agronegcio-brasileiro-em-
numeros>. Acesso em: 10 dez. 2012 .

Chicago Exchange Futures Market - CME Group. Data. Disponível em: <http://www.cmegroup.com > . Acesso em: 20 fev. 2013.

COBLE, K. H. et al. An Expected Indemnity approach to the Measurement of Moral Hazard in Crop Insurance. American Journal of Agricultural Economics, v. 79, p. 21626, fev. 1997.

FARMDOC, Farm Insurance. 2010. Disponível em: $<$ http://www.farmdoc.illinois.edu/cropins/index. asp>. Acesso em: 10 jan. 2012. 
FAO - Food and Agriculture Organization of the United Nations. FAO statistical yearbook 2013: world food and agriculture. Roma, 2013.

GENTON, M. Skew-elliptical distributions and their applications. Chapman \& Hall/CRC. London, 2004.

GOODWIN, B. K., ROBERTS, M. C. e COBLE, K. Measurement of price risk in revenue insurance: implications of distributional assumptions. Journal of Agricultural and Resource Economics. Bozeman, v. 25, n. 1, p. 195-214, jan. 2000.

HENZE, H. A probabilistic representation of the skewnormal distribution, Scand J. Statist, v. 13, p. 271-275, 1986.

ISU - Iowa State University. Crop revenue insurance. 2009. Disponível em: < http://www.2.econ. Iastate.edu/ research/webpapers/paper_10259.pdf $>$. Acesso em: 10 dez. 2012.

MEDEIROS, E. A. Avaliação da implementação do programa de subvenção do prêmio do Seguro Rural. Revista de Economia e Sociologia Rural, Brasília, DF, v. 51, n. 2, p. 295-308, 2013.

OZAKI, V. A. Métodos Atuariais aplicados à determinação da taxa de prêmio de seguro agrícola: um estudo de caso. 2005. 347 p. Tese (Doutorado em Economia Aplicada) - Escola Superior de Agricultura "Luiz de Queiroz", Universidade de São Paulo, Piracicaba, 2005.

. Análise espacial da produtividade agrícola no estado do Paraná: implicações para o seguro agrícola.
Revista de Economia e Sociologia Rural, v. 46, p. 869-886, 2008.

. Uma digressão sobre o programa de subvenção ao prêmio do seguro rural e as implicações para o futuro do mercado do seguro rural. Revista de Economia e Sociologia Rural, Brasília, DF, v. 48, n. 4, p. 757-776, 2010.

., GOODWIN, B. K. e SHIROTA, R. Parametric and non-parametric statistical modeling of crop yield: implications for princing crop insurance contracts. Applied Economics, v. 40, p. 1151-1164, 2008.

. e SILVA, R. S. Bayesian ratemaking procedure of crop insurance contracts with skewed distribution. Journal of Applied Statistics, v. 36, p. 443-452, 2009.

SANTOS, C. O., SCALON, J. D. e OZAKI, V. A. A Distribuição Normal-assimétrica como modelo para produtividade de milho aplicada seguro agrícola. Revista de Economia e Sociologia Rural, v. 52, n. 4, p. 725742, 2014.

SHERRICK, B. J. et al. Crop Insurance Valuation under Alternative Yield Distributions. American Journal of Agricultural Economics, v. 86, n. 2, p. 406-419, 2004.

SKEES, J. et al. The Potential for Revenue Insurance Policies in the South. Journal of Agricultural and Applied Economics. Minneapolis, v. 30, n. 1, p. 47-61, jul. 1998.

USDA/RMA - United States Departament of Agriculture - Risk Management Agency. Crop Insurance Handbook. Disponível em: <http://www.rma.usda. gov>. Acesso em: 10 jan. 2014 